\title{
BlockChain (BC) Upending Customer Experience: Promoting a New Customer Relationship Management (CRM) Structure Using Blockchain Technology (BCT)
}

\author{
Mohamad Abu Ghazaleh ${ }^{1}$ \& Abdelrahim M. Zabadi ${ }^{2}$ \\ ${ }^{1}$ DBA, An innovation digitalization leader, Abu Dhabi, UAE \\ ${ }^{2}$ PHD in management information systems, Amman, Jordan \\ Correspondence: Mohamad Abu Ghazaleh, Abu Dhabi, UAE. E-mail:mohammed.abughazaleh@gmail.com
}

Received: March 27, $2021 \quad$ Accepted: April 30, $2021 \quad$ Online Published: May 7, 2021

doi:10.5539/jms.v11n1p203 URL: https://doi.org/10.5539/jms.v11n1p203

\begin{abstract}
This study aims to explore the role of BC and its impact on CRM by suggesting an extended CRM on the basis of $\mathrm{BC}$ capabilities thru developing an analytic hierarchy planning-based framework to establish criteria weights developing a new self-assessment model to determine the most critical factors impacting the BC investment in $\mathrm{CRM}$ to enhance customer experience and to enable parties to work together in a trusted technology environment.

An analytical hierarchical process (AHP) approach was utilized to prioritize and weigh the factors affecting the $\mathrm{BC}$ investment in modern CRM in the service industry based on the extant literature and its interpretation. This approach resulted in a ranking of 19 sub-factors based on experienced customer service professionals and technologists' evaluations. Findings revealed a significant insight into proposing a new generation of CRM based on $\mathrm{BCT}$, focusing on using the powerful $\mathrm{BC}$ platform considering all factors influencing the $\mathrm{BC}$ investment in modern CRM from a business perspective. Understanding the new combination of BC and CRM can solve the challenges and dilemmas linked to the untrusted environment of handling CRM data in the information systems field. This study provides valuable information and critical analysis of BC regarding CRM integration. Directions for future research are also included.
\end{abstract}

Keywords: customer relationship management (CRM), block chain, analytic hierarchy planning framework (AHP)

\section{Introduction}

Firms that aim to sustain success should start exploring options for investing in $\mathrm{BC}$ initiatives that focus on cost reduction and enhancing competencies and seizing new opportunities to create a novel customer value. Nowadays, firms consider that modern CRM resolves customer problems by integrating front, middle, and back offices thru proactively addressing and instantly handling common requests in a trusted database.

$\mathrm{BC}$ can be a suitable environment to embrace a trusted CRM. Over and above, BC possesses the capacity to reconfigure new industries in future decades (Clohessy \& Acton, 2019). However, the adoption of BC in CRM solutions remains under research. Thus, this study analyses and develop an analytical hierarchy planning-based model to establish criteria weights and to develop a generic self-assessment model to specify the most important factors that impact BC investment in CRM.

Thru this suggested model, the present study contributes to the field by specifying the main business sectors that employ BC in CRM, and by revealing fundamental descriptions on these areas. Such innovative business models related to a combined CRM and $\mathrm{BC}$ will assist professionals and technologists in understanding this new niche of expertise.

This study builds on the BC concept which defined by Memo et al. (2015) as a database with main characteristics (i.e., decentralization, security, reliability, encryption, and information automation). Despite the plenty of available opportunities and strategic importance of BC for many businesses, the adoption of this technology remains the most significant challenge and overwhelms the world due to the great achievement of digital currency (Prince et al., 2020). The CRM-BC base can create new experiences for customers, quicken 
evolvement, and drive a worthy customer value (KPMG, 2018). Extant literature on BC and CRM either addresses a specific application area in BC or CRM separately or focuses on a subset of BCTs. To overcome this gap, this research takes a more thorough sight at $\mathrm{BC}$ technologies with focusing on their probable effect on CRM.

Reviewing literature aims to obtain an explanation on how BC capabilities will provide an ideal and secure CRM platform for business environments, such as privacy, integrity, data security (Kaur \& Kaur, 2018). After the introduction of the fourth $\mathrm{BC}$ computing wave, it has been evidence that a trusted environment was missing from the prior wave of technology. New CRM can be promoted with a trusted environment in a faster manner in handling data by introducing the new BCT. This paper also explains the basic concepts, features, and discussions of the new BCT, and then discusses and criticizes the research in this area.

Besides, it addresses the characteristic features of BCT, its applications, and its relation to CRM platforms. Finally, by integrating the $\mathrm{BC}$ and CRM platforms, the author outlines a set of new CRM features that can be introduced by integration with BCT. The CRM-BC base will introduce a valuable and accurate database of customer information to show the current needs and wants of customers. To address the research objective, the research question was formulated as follows: "In modern customer service powered by BCT, how to create dynamics and an effective CRM in the service industry"?

\section{What is $\mathrm{BC}$ ?}

$\mathrm{BC}$ has evolved as an effective technology enabler in several fields to solve many security and privacy issues (Shrestha et al., 2020). BC is defined as "a chain of blocks, where each block contains records". Moreover, each block is connected to other blocks cryptographically. Memo et al. (2015) defined these records as a database with basic characteristics viz decentralization, security, reliability, encryption, and information automation. Most modern CRM databases are hosted on Cloud servers, making the CRM database always exposed to the threat. Moving the CRM database into an Internet-based cloud platform will require a significant investment in data security and privacy (Kaur \& Kaur, 2018).

As per Peterson (2018), BC is a novel technology that can be utilized to store, structure, and transfer data, it is known as a decentralized data "distributed ledger." There are two aspects of BC technology: (1) the "Block" refers to the data package; (2) the "Chain" of BC is represented by utilizing a "hash" of each Block where each Block also has an indicator that refers to the next and prior Blocks. These interlocking hashes shape the second aspect of BC (the chain). Pierro (2017) also defined BC as hashing technology, which is at the basis of new technology platforms for trading and executing smart contracts (SC).

\section{CRM \& BC: An Ideal Combination to Efficient CRM Suggestion}

Nowadays, considering that most CRM databases are hosted on cloud servers, the security of the Cloud data still the main concern for business owners. Prior studies, for example, Anand (2017) have reported security concerns that include data leakage risks, risks to the security of cloud-based services, risks of sharing platform resources, and attacks on stored data. While other studies such as Kaur and Kaur (2018) are concerned with data security, data privacy, data loss, data leakage impact on the business industry, impact on organization business brand, and trust.

Customer excellence and their experience are often discussed in corporate board rooms of large enterprises. Notwithstanding, given the changing nature of customer experience in the entire of his journey, a new technology, like BC and artificial intelligence (AI), strengthens the customer experience and offers a new change in the digital customer revolution. Batra (2019) referred to how new technologies can change customer service excellence, and how practitioners may benefit in acquiring an understanding of how to utilize such kind of new technological advancements to strengthen customer experiences.

$\mathrm{BC}$ is a technology that can renovate customer experience and the way(s) how we accomplish business. It is yet another emerging technology that promises different business industries similar to AI and big data (Vijay, 2018). Recent studies have asserted that large firms, like Airbnb \& Uber, could be potentially operated in the future by $\mathrm{BC}$ technology. $\mathrm{BC}$ can overcome overbooking, fraud, traveller profiles, compliance, and SC (Purcărea \& Purcărea, 2017). Other studies for example (Martinez et al., 2019) have investigated how BC will offer clear traceability, visibility, and secure transactions. Following are divergent areas in CRM that are likely to benefit the most from BCT.

\subsection{Enhancing Security}

$\mathrm{BCT}$ has been reported to have the potential to eliminate one of the most significant obstacles to economic growth in developing countries due to the lack of trust (Fandl, 2020). Therefore, any leakage of data security will 
affect the business brand and trust of organizational products. Resources sharing of cloud platforms among multiple firms will create data misuse. Securing the data storage of cloud platforms is essential to avoid such risks. The protection of data is the main challenge in the CRM cloud. Looking after the authentication and authorization of stored data is crucial also (Anand, 2017). BC encryption technology is used to secure information passes between different sites (Helfand, 2017). BCT allows data transfer between customers, suppliers, and other parties (Thorn, 2018).

Confidentiality is one angle to enhance security in cloud computing by investing in BC. Ensuring that data are protected from any possible attacks is necessary. Storing data on a cloud platform raises serious issues that are linked to data privacy, and a significant challenge is data confidentiality (Shrestha et al., 2020). Thus, security authentication and ongoing check must be conducted to protect the cloud data from malicious users who can manipulate access control mechanisms and as cross-site scripting (Kaur \& Kaur, 2018).

Customer personnel data confidentiality becomes a real business challenge. BCT systems can potentially help in keeping customer data confidential and allowing the easy sharing of data between organizations (Pulwasha et al., 2020). Prior studies (e.g., Kaur \& Kaur, 2018; Tian et al., 2019) have also reported data availability as one of the security threats and one of the most critical issues in a business-facing downtime and threats on service providers and highly concerned to have a new technology implemented to secure cloud CRM computing services.

Data integrity is vital to guarantee the smooth operation of business activities (Tian et al., 2019). Anand \& Jha (2019) defined data integrity as "data accuracy and consistency stored in a cloud database to ensure that data characteristics are correct, such as how malicious the alteration of cloud data has been done". Therefore, BC is the solution for any malicious attacks to avoid missing and retrieving data (Sharma et al., 2018). Some more concerns are the locality of cloud computing and how the data are distributed over different locations may create compliance and data privacy issues, impacting the governing laws in cloud computing that affects the governing law of the data (Shrestha et al., 2020). Finally, data access is another challenge that refers to access to a particular section of data over a cloud platform, considering some restrictions that other employees cannot access data within the same organization (Kaur \& Kaur, 2018). Hence, various encryption techniques thru BC can be introduced to ensure that data are saved and shared only with authorized users. This is another challenge to protect data from any external modifications (Shrestha et al., 2020).

\subsection{Maintaining Better Ttransparency}

Today, in any enterprise system, data transparency is essential, because, in managing customer data, trust is a critical issue in any business relationship. In today's complex business environment, we must embrace transparency in new and meaningful ways to give customers new ownership of their data and provide them with answers and status updates to their issues right away. From a customer relationship point of view, transparency is defined as "the degree of the accessibility of relevant information for customers".

Further, previous research (e.g., Sung-Bum \& Dae-Young, 2016) has proven that transparency has a significant influence on customer relationships and trust, and customer trust has a significantly positive influence on customer loyalty and strengthens the organization-customer relationship. This shows how this component is vital in CRM products. Dubbink et al. (2008) stated that transparency is necessary and critical nowadays for corporate social responsibility.

BCT promises the transparency of information by offering auditable and valid transactions and achieving end-to-end transparency (Collomb et al., 2019). Transparency means that BC represents a decentralized database environment for all transactions, where all these transactions are recorded and visible to all users. The reason is that coding and data encryption in BCT improve transparency and trust in information sharing (Cole et al., 2019).

Therefore, BCT is expected to be a transparency tool or platform in which anyone can view all encrypted information on that network through an encryption protocol mechanism. With efficient, visible, immutable, and honest information due to decentralize networks (Cole et al., 2019), BC transparency will be the core of BCT by having the same transaction recorded across extensive network transparency, which will make it easy for users to view every transaction. New emerging technology in customer services around BC is SCs.

This new technology is capable of executing legal agreements far more complicated by keeping a record for every access and modifying transactions in BC by creating new transactions of versions (Goldenfein \& Leiter, 2018). Contract legislatures should take proactive steps to regulate such new SCs and ensure transactions for smart contract parties. The SC will set a decentralized network that can keep user data safe and allow for transactions between parties who may not trust one another (Arcari, 2019). 
Moreover, SC will enhance customer journey and trade efficiency and reduce transaction costs between parties. SC supported by BC technology are expected to be used for international trade agreements and for the future of trade (Duke, 2019). Thus, it is likely that SCs can function in a similar way to traditional contracts but by offering more secured and trusted solutions due to the open architecture used by $\mathrm{BC}$, which is publicly accessible, verifiable, and immutable (Fandl, 2020).

Adopting BC will enable traceable and faster transactions thru SCs (Balci et al., 2019). Look at cyber security. Previous studies have discussed that a decentralized BC is supposedly much more secure (Kim, 2019). Therefore, the amount of efforts and time to invest in securing BC components is the key (Mearian, 2019). BC developers must put considerable investment to get to the bottom line of BC security. Firms must also examine the entire digital ecosystem when considering security (Kim, 2019).

$\mathrm{BC}$ allows firms to transparently and securely deal with their customers without the need for a financial institution or a third-party broker. Hence, introducing the CRM-BC will lead to eliminating these parties and bringing greater efficiency and speed in the customer journeys of companies. Financial institutions have faced a growing volume of cyber-attacks in recent years thru sophisticated techniques (Creado \& Ramteke, 2020). The BC platform has the potential to represent an innovative way of transforming financial services (Evangeline \& Wilner, 2017). Firms nowadays use BC technology as part of their digital transformation journey (Moyo et al., 2019).

\subsection{Data Challenges}

Due to large volumes and different sources of CRM structured business data require significant effort to maintain and qualify the data, the pain experienced from low quality of the growing data more acute (Bidlack \& Wellman, 2010). Therefore, CRM business users all over any digital platform must deal with duplicate or inaccurate data to some extent. Data quality in CRM platforms, low-quality data result from capturing them manually into the CRM system sometimes by users in CRM directly or thru web integration without paying attention to their quality (ibid).

The CRM data captured by system users are used for operational purposes. Any misspellings, missing information, and abbreviations in the data will impact the ability of an organization to leverage the data for operation purposes. Data quality is crucial to produce improved business practices and results (Crié \& Micheaux, 2006). Price Waterhouse Coopers $(\mathrm{PwC})$ understood this matter and launched a new program in late 2018, focusing on data cleansing issues using $\mathrm{BC}$ technology. The program covers data analytics and cleansing data using $\mathrm{BC}$. With $\mathrm{BCT}$ in place, customers will have a unified key that presents their personal information, historical transactions, and subscriptions (PWC, 2018). Hence, BC helps resolve inaccurate and duplicate data, offers better insights into customer data, and helps businesses and customer engagement more effectively.

One of the biggest challenges faced by the world in the current digital era is technology expansion, which results in generating a massive amount of data by users and machines linked to the Internet using the concept "Internet of things (IoT)" (Mohamad \& Zabadi, 2020). After releasing the latest IoT applications and the proposed connection with CRM (ibid). Internet connectivity reaches humans and most of the devices in our environment, thereby connecting billions of devices simultaneously, which is a challenge in processing data to improve our lives and serve customers better.

Previous research has provided an overview of the integration of BC with the IoT and CRM (Atlam et al., 2018; Mohamad \& Zabadi, 2020) and has discussed its benefits and challenges. All data sources that will benefit organizations and customers will be collected from various data sources, directly and indirectly, and will impact CRM data quality and customer performance. Maroofi and Amiri (2016), in their study of examining how data collection impacts CRM data quality and customer performance, concluded that customer touch point data are finally led to CRM system quality and performance. Hence, the role of CRM system quality supported by BCT is essential for firms to increase their market insight and performance. BCT promises the best way to organize and process big data (Karafiloski \& Mishev, 2017).

Current CRM platforms with limited CRM data sources without connecting with BC and new feeder systems will not support and satisfy the on-going business changes (Vernon, 2000; Afifi-Sabet, 2019). Therefore, new platforms must be established to get the information into CRM continuously. Salesforce has recently connected with the $\mathrm{BC}$ platform with its CRM to allow their customers to create workflows and applications in a way that is easier than traditional methods. Adding the BC network on the top of CRM will allow CRM users to add additional data on the top of existing data related to sales, service, and marketing modules and then run some other digital products, such as AI-powered algorithms, to integrate the data into sales forecasts and other predictions (Afifi-Sabet, 2019). 
In addition, data availability is another important aspect of CRM applications, and the availability of the customer information around the clock thru CRM to concerned users will introduce new ways for companies to interact with their customers (Lawson-Body et al., 2006). Working with BCT increases the availability of CRM platforms and will eliminate the single point of failure associated with the centralized structure without the need for the centralized server (Maroofi \& Amiri, 2016). Tian and Ding (2019) discussed how to manage medical data availability with the support of BC. The proposed system using blockchain could guarantee medical data availability, which can be easily deployed and implemented in CRM.

\subsection{Smart Loyalty Programs}

Loyalty programs are considered the most popular "value-added" CRM strategies to increase customer retention, reward frequent customers, and understand customers (Lo et al., 2017; Dominguez et al., 2020). Some studies have asserted that loyalty programs increase purchase frequency and operational profit by lowering expenses in recruiting new customers (Lo et al., 2017). CRM is used to maintain relationships with existing and new customers thru loyalty programs by rewarding them for repeated purchases and offer relational benefits in customer service and sales.

Loyalty programs aim to drive organization profit and enhance customer experience on the basis of customer data base and their preferences and behaviours (Lee, 2008). In response to the current era of technology and competition in demanding customers, CRM has been released lately in the past few years addressing new loyalty program tactics as a loyalty program has become an important strategy to increase revenue and keep customers (Omar et al., 2010).

Notwithstanding, due to the current challenges in operating a loyalty program and the complexity for retailers to manage balances, brands, collections, and card ownership (Dominguez et al., 2020). This paper proposes a new CRM loyalty structure program on the basis of a $\mathrm{BC}$ platform that does not require a physical card for identifying customers. Businesses are still facing several bottlenecks and challenges with traditional customer loyalty programs due to the fast-moving consumer goods industry in divergent business clusters, such as payback process complications and lost card and paper-based process (Bulbul \& Ince, 2018; Wang et al, 2019).

In addition, traditional customer loyalty programs have several bottlenecks, such as lost paper-based coupons and payback process complications (Bulbul \& Ince, 2018). Considering all previously reported challenges, companies can reduce overhead costs associated with the operation of an entire loyalty program due to high prices paid to set up and maintain their third-party solutions and integrations with customer loyalty programs (Dominguez et al., 2020). Loyalty programs will lower expenses in recruiting new customers (Lo et al., 2017). Using BCT has the potential to address these challenges, and companies, such as Cathay Pacific, Lufthansa, and Singapore Airlines, are already investing in BC-based loyalty programs (Atul \& Urjita, 2019). Therefore, operating a loyalty program is highly complicated and requires to manage customer balances, point collections, and transfers of customers.

Another fact is that customers are now carrying too many cards, which is impractical; customers may forget, and proposing loyalty on the basis of CRM-BCT companies can reduce overhead costs associated with managing loyalty programs (Dominguez et al., 2020). According to Rosenoer (2019), BC can reduce 30\% of back office service costs, particularly those related to day-to-day reconciliation and bad data. With the CRM-BC based digital wallet, KPMG (2018) proposed a straightforward process for encouraging retailers to connect with the program and customers to process purchases with their miles using BCT. Such a solution will provide real-time stamps for every customer transaction, which provides high cost and time efficiencies.

Retailers use loyalty programs to increase customer retention by collecting specific customer data and to identify a particular customer to enable individualized marketing at the customer level (Dominguez Perez et al., 2020). CRM data based on $\mathrm{BC}$ can be shared securely and reused across business units within organizations, which leads to better customer satisfaction and increase client retention (Rosenoer, 2019). BC is changing digital marketing by increasing customer retention through marketing channels, and $\mathrm{BC}-$ based web can interact with customers thru online advertising. Customers' website visitors can view ads and receive basic attention ads with which they interact. As per Balci et al. (2019), adopting BC will enable traceable and faster transactions. In this way, such a service will increase the loyalty of customers.

Moreover, BCT with big data is expected to significantly reduce clutter and waiting times at the point of interactions with customers (Jha, 2017). Thus, BC can be employed at diverse stores and brands. Consumers will not have to juggle with points issued from retailers, airline miles, and food restaurant stamps. Speaking of CRM-BC solutions for loyalty programs, a new innovative solution will transform reward and traditional loyalty programs to improve the brand offerings of companies. 
The role of branding is crucial in delivering the promise of companies to their consumers in a competitive global market, and it is the key to reassuring them of product quality (Veloutsou \& Moutinho, 2009). BC applications can affect customer-brand relationships, which makes BC essential in strategic brand management, such as brand storytelling, brand transparency, and trust for brands in online marketplaces, among others, and the adoption of digital currencies (ck, 2019). Previously, brand managers have used multiple marketing approaches to reach their customers and pass their brand messages.

The rise of the social media channels has disrupted traditional brand communications and has shifted the focus and scope of brand management to a new online direction called technology-mediated interaction (Kohli et al., 2015; Boukis, 2019). In this era of digital BCT provides new opportunities for brands to foster their relationships with consumers (Boukis, 2019). Therefore, companies can integrate such emerging new technologies in their branding. "BC" has become increasingly popular over the past few years in various industries, such as airlines, retailers, and financial services.

Previous studies have recommended that company brands should benefit from new BCT and look for new ways to deliver their brand promise in an error-free way to their customers (Pachamanova et al., 2017; Boukis, 2019). E-commerce has experienced exponential growth in the past few years, and this growth causes various problems, such as disconnecting between online and in-store shopping and continuously changing consumer behaviours. Recently, the digital industry has released BC-based platforms to have a better connection between retailers and shoppers. These platforms aim to connect brands, retailers, and shoppers' altogether. These platforms will also examine the customer behaviours and introduce unique experiences (Reckoon, 2020), thereby improving brand sustainability and overall shopping experience.

\section{Method}

\subsection{Process}

The nature of this case study is exploratory, and its goal is to apply the new proposed CRM-blockchain framework in a practical setting and present the expected results. All interviews were conducted in customer service excellence business centres. Figure 1 presents an outline of the process employed in this research. The current study proposes a tested Analytic Hierarchy Process (AHP) framework to establish new criteria weights and develop a generic self-assessment model to determine the most critical factors influencing CRM-BC investment and prioritize and identify new business-required factors while implementing blockchain and CRM technology. 


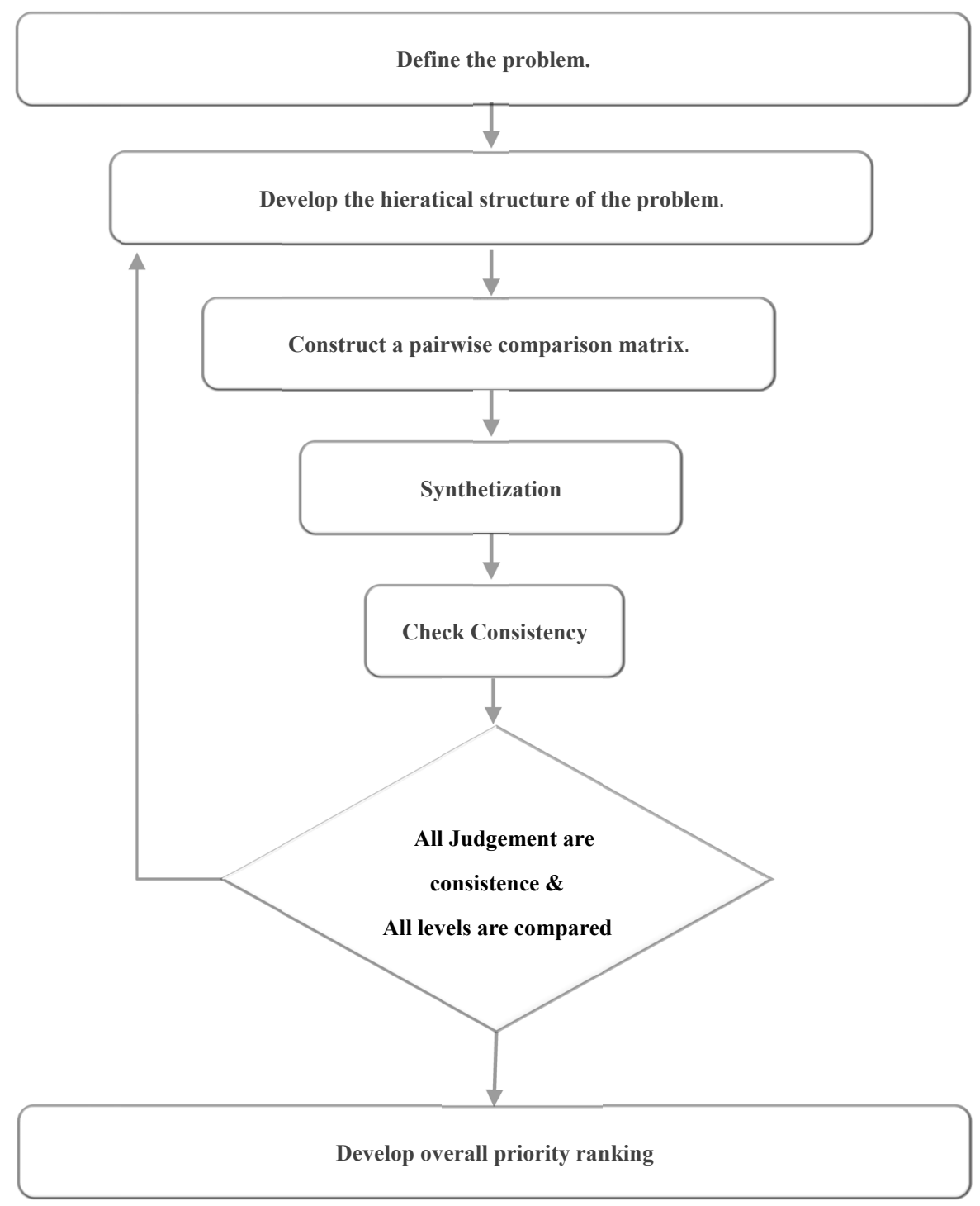

Figure 1. Outline of the AHP method applied

Source: Mohamad and Zabadi, 2020.

In order to decide which business factors are the most important to the new modern CRM cloud base, the study processed by applying the AHP approach. It is highly recommended for solving complex and hierarchical problems that cannot be solved using purely quantitative methods (Morkunas et al., 2019; Shoaib et al., 2020). Hence, this study identified and prioritized the factors that influence the implementation of a CRM-BC base via an integrated framework. The research was also conducted in a customer service excellence business centre using a new CRM system without any BC connectivity in 2019. Our contact with the relevant departments in the customer service excellence business center aims to identify and obtain the most critical factors that influence a CRM-BC base. Twelve experts were identified in customer service excellence.

\subsection{Proposed Model}

As shown in Figure 2, identifying the research problem is the first step in the model followed by identifying, prioritizing, and selecting factors that influence a successful CRM-BC base. In addition, Figure 2 illustrates the proposed CRM-BC hierarchy on the basis of the AHP model. The multi-criterion that contains four successful factors is listed under level 2, and the sub factors that illustrate and measure those factors are listed under level 3. There are 21 sub-criteria distributed on the four factors of level 2. 


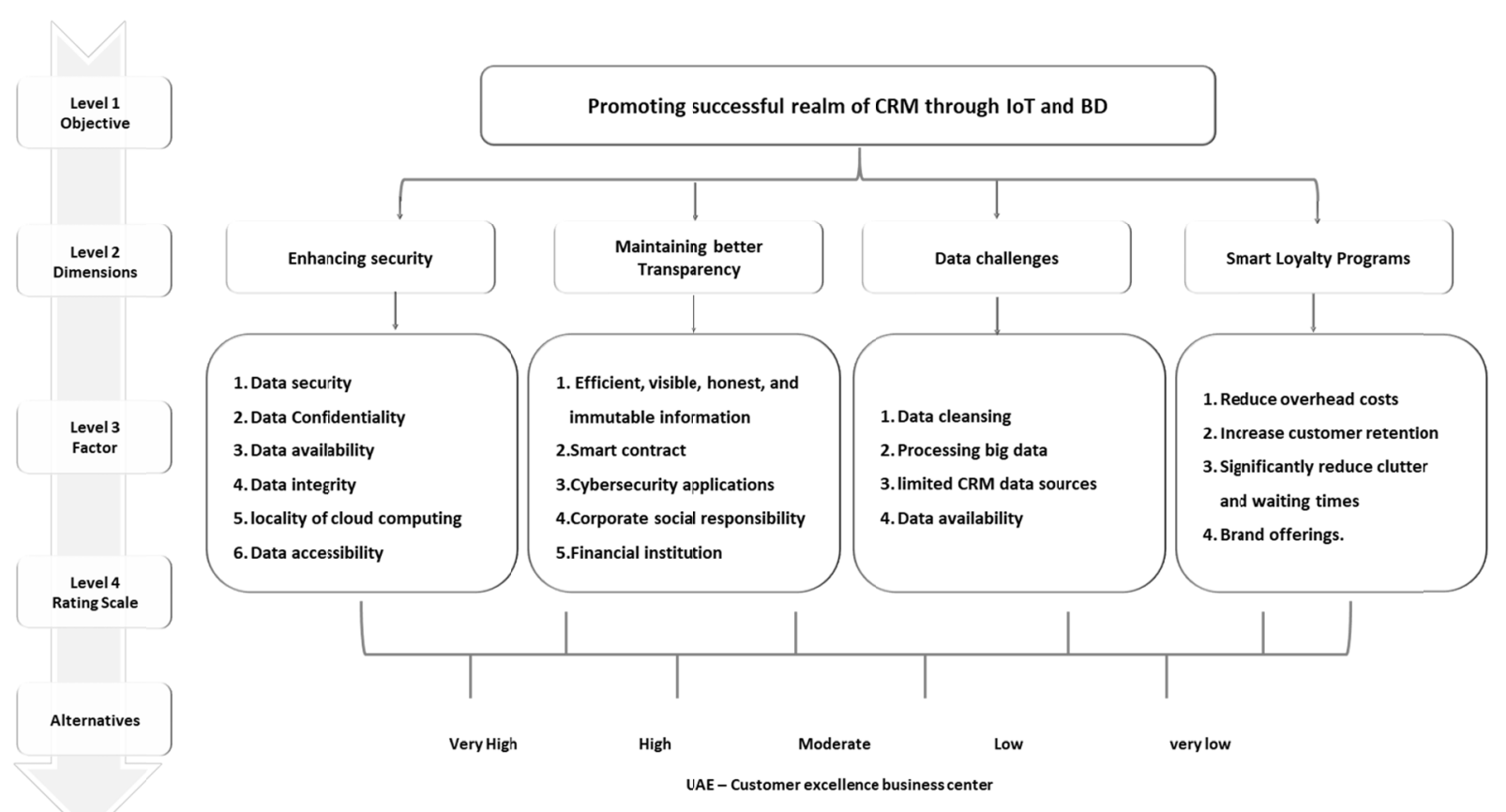

Figure 2. Hierarchy for the newly proposed CRM-BC model

Source: Mohamad and Zabadi, 2020.

The questionnaire was designed on the basis of the nine-point scale proposed by Baba et al. (2017) for a pairwise comparison (see Table 1).

Table 1. Nine-point scale for an AHP pairwise comparison

\begin{tabular}{lll}
\hline Intensity of importance & Definition & Explanation \\
\hline 1 & Equal importance & Two criteria contribute equally to the objective of waste reduction. \\
3 & Moderate importance & Judgment slightly favours one over another. \\
5 & Strong importance & Judgment strongly favours one over another. \\
7 & Very strong importance & A criterion is strongly favoured, and its dominance is demonstrated in practice. \\
9 & Absolute importance & Importance of one over another affirmed on the highest possible order \\
$2,4,6,8$ & Intermediate values & Used to represent compromise between the priorities listed above \\
\hline
\end{tabular}

Source: Mohamad and Zabadi, 2020.

The research data were collected from six organizations in Abu Dhabi, UAE that host large business centres to support their customers. Seven employees held senior managerial positions in investor relationship management with CRM and at least 12 years of experience managing customer relationships and implementing digital customer transformation strategies. The interviews were conducted thru a face-to-face meeting to collect their opinions. Drake et al. (2013) validated that the AHP approach requires a small sample size to report reliable results. As Scala et al. (2016) suggested, instead of the arithmetic mean, the geometric mean was used to conclude and report pair-wise matrices.

For instance, if an evaluator identifies that data cleansing is moderately more important than processing big data, then the former is rated " 3 " and the latter as " $1 / 3$." Post completing the evaluation, the global weights and maximum eigenvalue $(\lambda \max )$ and the eigenvectors for each matrix were calculated. Additionally, the lmax value as a reference index was employed to calculate the consistency ratio (CR) of the estimated vector to assess whether matrices are sufficiently consistent. The consistency was defined as $C I=[(\chi \max -n) /(n-1)]$. The CR is the ratio of the $\mathrm{CI}$ to the random index (RI), $\mathrm{CR}=\mathrm{CI} / \mathrm{RI}$. The ransom index (RI) is given in Table 2 of Drake et al. (2013). 
Table 2. Random index

\begin{tabular}{lllllllllll}
\hline $\mathbf{N}$ & 1 & 2 & 3 & 4 & 5 & 6 & 7 & 8 & 9 & 10 \\
\hline $\mathbf{R I}$ & 0.00 & 0.00 & 0.58 & 0.90 & 1.12 & 1.24 & 1.32 & 1.41 & 1.45 & 1.48 \\
\hline
\end{tabular}

The study was built upon the $\mathrm{CR}$ rate. Therefore, the inconsistency of a matrix is acceptable if its CR is less than or equal to 0.10 (Drake et al., 2013).

\section{Results and Discussion}

Table 3 shows that the enhancing security attribute was considered the most important by the reviewers, with a priority weight of $47 \%$, followed by data challenges, which had a competitive priority of $29 \%$. Smart loyalty programs ranked third, and maintaining better transparency was considered the least important attributes by the evaluators. Thus, enhancing security in a CRM-BC base can provide valuable insight that can help protect the ability of organizations to operate and enables the safe operation of enterprise systems, protects the data that organizations use, and safeguards the technology that organizations employ. Therefore, the benefits of BC \& CRM combined can assure maintaining the security standard challenges in organizations and increasing the interconnected environment and can offer more sacred solutions to increasing threats, such as malicious code, denial-of-service attacks, and computer hacking.

Sharma et al. (2019) reported that blockchain could maintain and hold sensitive data in an encrypted and secured manner to avoid any mid-way alterations possible in a transaction. Hence, this paper aims to provide a detailed analysis of the importance of $\mathrm{BCT}$ in serving company securities to explain some important terminologies related to BC security and provide insight into BC-based CRM. Given the fourth industrial revolutions and the increase in smart cities and smart factories, the number of IoT devices has been increasing, and the security of these connected devices has also become a new challenge accordingly due to cyber-attacks, such as man-in-the-middle and roll-back attacks.

Accordingly, Son and Kim (2019) proposed a new firmware architecture using BCT to ensure the data's integrity and security resulted from the IoT devices. This result is beneficial for technology executives looking after developing and upgrading enterprise systems and formulating a strategy to achieve a fully secured CRM platform with BC support. To better understand the concluded priorities, the study reported the four successful realms of CRM thru BCT. Table 4 shows the ranking of the pair-wise comparison of the sub-criteria under each factor to validate whether the CR acceptability.

Enhancing security (Table 4) had six sub-criteria: data security, data confidentiality, data availability, data integrity, locality of cloud computing, and data accessibility. Data security had the highest weight (33\%), followed by data confidentiality (26\%). Data integrity and data availability scored $13 \%$, and data accessibility and locality of cloud computing ranked fourth and fifth, respectively, (9\% and 6\%). Locality of cloud computing had the lowest weight $(6 \%)$.

Table 4 displays the pair-wise comparison of the second data challenge sub-criterion. Predicting processing big data was considered to be the most important by the reviewers, with a priority weightage of $33 \%$, followed by data availability, which had a competitive priority of $31 \%$. Limited CRM data sources and data cleansing ranked third and fourth, respectively, (21\% and 15\%). Moreover, Table 4 displays the pair-wise comparison of the third smart loyalty program sub-criterion. Increasing customer retention was considered to be the most important by the respondents, with a priority weightage of $43 \%$, followed by brand offerings, which had a competitive priority of $27 \%$. Significantly reducing clutter and waiting times ranked third $(21 \%)$, and reducing overhead costs ranked last, with $9 \%$.

Maintaining better transparency (Table 4) had five sub-criteria: SC, immutable information, cyber security applications, financial institution, and corporate social responsibility. Financial institution had the highest weight (32\%), followed by efficient, visible, honest, and immutable information (31\%). SC, cyber security applications, and corporate social responsibility ranked third, fourth, and fifth, respectively $(17 \%, 15 \%, \& 4 \%)$.

Table 3. Geometric means of the pair-wise comparison of the main criteria

\begin{tabular}{llllll}
\hline & $(\mathbf{A})$ & (B) & (C) & (D) & Priority vectors \\
\hline Enhancing security & 1.00 & 4.30 & 2.20 & 2.80 & 0.47 \\
Maintaining better Transparency & 0.23 & 1.00 & 0.42 & 0.62 & 0.10 \\
Data challenges & 0.45 & 2.40 & 1.00 & 3.30 & 0.29 \\
Smart loyalty programs & 0.36 & 1.60 & 0.30 & 1.00 & 0.14 \\
CR value: $0.03<0.10$ (consistent). & & & & & \\
\hline
\end{tabular}


Table 4. Average of the pair-wise comparison of sub-criteria

\begin{tabular}{|c|c|c|c|c|c|c|c|}
\hline \multicolumn{8}{|c|}{ Average of the pair-wise comparison of sub-criteria (enhancing security) } \\
\hline Criteria & (A) & (B) & (C) & (D) & (E) & (F) & Priority vectors \\
\hline Data security & 1.00 & 2.70 & 5.10 & 2.80 & 2.30 & 2.22 & 0.33 \\
\hline Data confidentiality & 0.37 & 1.00 & 4.70 & 4.30 & 2.60 & 2.00 & 0.26 \\
\hline Locality of cloud computing & 0.20 & 0.21 & 1.00 & 0.61 & 0.29 & 0.71 & 0.06 \\
\hline Data integrity & 0.36 & 0.23 & 1.64 & 1.00 & 1.11 & 2.10 & 0.13 \\
\hline Data availability & 0.43 & 0.38 & 3.48 & 0.90 & 1.00 & 1.31 & 0.13 \\
\hline Data accessibility & 0.45 & 0.50 & 1.41 & 0.32 & 0.76 & 1.00 & 0.09 \\
\hline \multicolumn{8}{|c|}{ CR value: $0.06<0.10$ (consistent) } \\
\hline \multicolumn{8}{|c|}{ Average of the air-wise comparison of sub-criteria (maintaining better transparency) } \\
\hline & (A) & (B) & (C) & & (D) & (E) & Priority vectors \\
\hline $\mathrm{SC}$ & 1.00 & 0.60 & 1.83 & & 0.51 & 3.60 & 0.17 \\
\hline $\begin{array}{l}\text { Efficient, visible, honest, and } \\
\text { immutable information }\end{array}$ & 1.66 & 1.00 & 1.85 & & 2.00 & 4.90 & 0.31 \\
\hline Cyber security applications & 0.55 & 0.54 & 1.00 & & 0.23 & 6.90 & 0.15 \\
\hline Financial institution & 1.97 & 0.50 & 4.41 & & 1.00 & 8.60 & 0.32 \\
\hline Corporate social responsibility & 0.28 & 0.20 & 0.14 & & 0.12 & 1.00 & 0.04 \\
\hline \multicolumn{8}{|c|}{ CR value: $0.08<0.10$ (consistent) } \\
\hline \multicolumn{8}{|c|}{ Average of the pair-wise comparison of sub-criteria (data challenges) } \\
\hline & (A) & (B) & (C) & (D) & & & Priority vectors \\
\hline Data cleansing & 1.00 & 0.82 & 0.49 & 0.29 & & & 0.15 \\
\hline Processing big data & 1.22 & 1.00 & 2.30 & 1.30 & & & 0.33 \\
\hline Limited CRM data sources & 2.03 & 0.43 & 1.00 & 0.78 & & & 0.21 \\
\hline Data availability & 3.42 & 0.77 & 1.28 & 1.00 & & & 0.31 \\
\hline \multicolumn{8}{|c|}{ CR value: $0.08<0.10$ (consistent) } \\
\hline \multicolumn{8}{|c|}{ Average of the pair-wise comparison of sub-criteria (smart loyalty programs) } \\
\hline & (A) & (B) & (C) & (D) & & & Priority vectors \\
\hline Reducing overhead costs & 1.00 & 0.26 & 0.35 & 0.26 & & & 0.09 \\
\hline Increasing customer retention & 3.86 & 1.00 & 2.30 & 1.66 & & & 0.35 \\
\hline $\begin{array}{l}\text { Significantly reducing clutter and } \\
\text { waiting time }\end{array}$ & 2.83 & 0.43 & 1.00 & 0.24 & & & 0.17 \\
\hline Brand offerings & 0.41 & 0.24 & 0.21 & 0.17 & & & 0.05 \\
\hline CR value: $0.08<0.10$ (consistent) & & & & & & & \\
\hline
\end{tabular}

\section{Conclusions}

BCT can transform today's business industry and has gradually become a vital part of our enterprise system infrastructure. The new BCT solutions will help empower all organizations to build new solutions toward a more connected world with the highest degrees of trust, transparency, and security to the business industry. It offers unprecedented opportunities to transform business modules in banking, retail, finance, and insurance. It is one of the technologies that will drive the technology strategy of enterprises shortly, improve end customer experience, and enhance operational efficiencies (Shukla, 2019). This paper aims to introduce a new CRM-BC base technology that will enhance security across various business models, and it is expected to improve traceability, reduce cost, and increase efficiency.

Competition nowadays relies on deploying innovative solutions to deliver a differentiated experience to customers. The vision of CRM adaptive BC functionalities in the process is becoming a reality, but further efforts are crucial toward the migration of CRM \& BC integration as firms must change their business models according to how to serve their customers. Previous studies (Lin et al., 2020; Balci et al., 2019; Power \& Weinman, 2018) have focused more on $\mathrm{BC}$ to improve financing modules, business performance, customer satisfaction, cost reduction, and service quality by leveraging BCT .

Therefore, this paper highlighted the significant benefits and how to invest in the new CRM-BC base features, which will allow organizations to enter into a new wave of technology to take customer experience to the next level by enabling firms to better understand their customer experiences. Such a new model of CRM \& BC integration will offer a new customer experience environment. There are many lessons learned from Salesforce after launching its CRM-BC platform to allow organizations to create system workflows in a way that make it easier and faster than traditional methods (itp.net, 2019). The most important thing is that data can be secured in a $\mathrm{BC}$ network as all users involved can verify and see each transaction transparently. 
Combining CRM functionalities with BC features can introduce new business processes and models across all CRM modules: marketing, sales, and services. Observing the new wave of technology in $\mathrm{BC}$ in relation to customer experience, one can say that there is no doubt that firms will find themselves in the new era of a new CRM-BC structure. This will allow firms to overcome the reported challenges in current CRM platforms and introduce new CRM features and functions to keep up with technological advances.

Firms must understand the new wave of BCT better and its relation with CRM platforms to respond faster to changes in their environment. It is very critical that CRM \& BC platforms decision makers take note of the fact that BC will transform organisations. Rust (2019) discussed how the awareness of BC is still lacking and undermining to respond to the $\mathrm{BC}$ changes, but still the lack of regulatory clarity and application integration is possibly the greatest barrier to the development of BC.

This paper aimed to expose technology decision makers to the growing importance of the $\mathrm{BC}$ and its integration with CRM, which has greater potential of changing customer experience and the CRM industry. BC and its expected relation with CRM were defined and discussed, and the future integration of CRM and BCT was outlined. Several examples to integrate CRM modules and BC were also discussed. Nevertheless, this study concisely explained the changes that might occur in CRM with the support of BCT in a very dynamic world. It is shown thru many examples of how BC has impacted CRM. Firms should also consider that there is still some ambiguity in the story and the lack of research on the integration of BC and CRM.

\section{References}

Afifi-Sabet, K. (2019, May 31). Salesforce launches blockchain platform for CRM. IT Pro, Retrieved from http://adu-lib-database.idm.oclc.org/login?url=https://www-proquest-com.adu-lib-database.idm.oclc.org/do cview/2233000223? accountid $=26149$

Anand, A. (2017). Cloud computing and cloud related security issues. International Journal of Advanced Research in Computer Science, 8(5), 1881-1884.

Anand, A., \& Jha, A. (2019). Application and usability of blockchain in cloud computing. I-Manager's Journal on Cloud Computing, 6(2), 26-34.

Arcari, J. (2019). Decoding Smart Contracts: Technology, Legitimacy, \& Legislative Uniformity. Fordham Journal of Corporate \& Financial Law, 24(2), 363-407. Retrieved from http://adu-lib-database.idm.oclc.org/login?url=https://www-proquest-com.adu-lib-database.idm.oclc.org/do cview/2293888214? accountid $=26149$

Atlam, H. F., Alenezi, A., Alassafi, M. O., \& Wills, G. B. (2018). Blockchain with internet of things: Benefits, challenges, and future directions. International Journal of Intelligent Systems and Applications, 10(6), 40. https://doi.org/10.5815/ijisa.2018.06.05

Atul, P., \& Urjita, T. (2019). Role of information and communication technology in improving loyalty program effectiveness: A comprehensive approach and future research agenda. Information Technology \& Tourism, 21(2), 259-280. https://doi.org/10.1007/s40558-018-00139-6

Baba, Y., Kallas, Z., \& Realini, C. (2017). Application of the analytical hierarchy process to evaluate consumer acceptance and preferences for omega-3 enriched eggs. British Food Journal, 119(7), 1459-1472. https://doi.org/10.1108/BFJ-06-2016-0261

Balci, G., Caliskan, A., \& Yuen, K. F. (2019). Relational bonding strategies, customer satisfaction, and loyalty in the container shipping market. International Journal of Physical Distribution \& Logistics Management, 49(8), 816-838. https://doi.org/10.1108/IJPDLM-02-2019-0051

Batra, M. M. (2019). Strengthening customer experience through artificial intelligence: An upcoming trend. Competition Forum, 17(2), 223-231. $\quad$ Retrieved from http://adu-lib-database.idm.oclc.org/login?url=https://www-proquest-com.adu-lib-database.idm.oclc.org/do cview/2343014949? accountid $=26149$

Bidlack, C., \& Wellman, M. P. (2010). Exceptional data quality using intelligent matching and retrieval. $A I$ Magazine, 31(1), 65-73. https://doi.org/10.1609/aimag.v31i1.2280

Boukis, A. (2019). Exploring the implications of blockchain technology for brand-consumer relationships: A future research agenda. The Journal of Product and Brand Management, 29(3), 307-320. https://doi.org/10.1108/JPBM-03-2018-1780

Bulbul, S., \& Ince, G. (2018). Blockchain-based framework for customer loyalty program. Piscataway: The 
Institute of Electrical and Electronics Engineers, Inc. (IEEE). https://doi.org/10.1109/UBMK.2018.8566642

Clohessy, T., \& Acton, T. (2019). Investigating the influence of organizational factors on blockchain adoption. Industrial Management \& Data Systems, 119(7), 1457-1491. https://doi.org/10.1108/IMDS-08-2018-0365

Cole, R., Stevenson, M., \& Aitken, J. (2019). Blockchain technology: Implications for operations and supply chain management. Supply Chain Management, 24(4), 469-483. https://doi.org/10.1108/SCM-09-2018-0309

Collomb, A., De Filippi, P., \& Sok, K. (2019). Blockchain technology and financial regulation: A risk-based approach to the regulation of ICOs. European Journal of Risk Regulation, 10(2), 263-314. https://doi.org/10.1017/err.2019.41

Creado, Y., \& Ramteke, V. (2020). Active cyber defence strategies and techniques for banks and financial institutions. Journal of Financial Crime, 27(3), 771-780. https://doi.org/10.1108/JFC-01-2020-0008

Crié, D., \& Micheaux, A. (2006). From customer data to value: What is lacking in the information chain? Journal of Database Marketing \& Customer Strategy Management, 13(4), 282-299. https://doi.org/10.1057/palgrave.dbm.3240306

Dominguez Perez, L. J., Ibarra, L., García-Fernández, A., Rumayor, A., \& Lara-Alvarez, C. (2020). A loyalty program based on wave's blockchain and mobile phone interactions. The Knowledge Engineering Review, 35. https://doi.org/10.1017/S0269888920000181

Drake, P. R., Dong, M. L., \& Hussain, M. (2013). The lean and agile purchasing portfolio model. Supply Chain Management, 18(1), 3-20. https://doi.org/10.1108/13598541311293140

Dubbink, W., Graafland, J., \& van Liedekerke, L. (2008). CSR, transparency and the role of intermediate organisations. Journal of Business Ethics, 82(2), 391-406. https://doi.org/10.1007/s10551-008-9893-y

Duke, A. (2019). What does the CISG have to say about smart contracts? A legal analysis. Chicago Journal of International Law, 20(1), 141-177. $\quad$ Retrieved from http://adu-lib-database.idm.oclc.org/login?url=https://www-proquest-com.adu-lib-database.idm.oclc.org/do cview/2348896723? accountid $=26149$

Evangeline, D., \& Wilner, A. (2017). The security and financial implications of blockchain technologies: Regulating emerging technologies in Canada. International Journal, 72(4), 538-562. https://doi.org/10.1177/0020702017741909

Fandl, K. J. D. (2020). Can smart contracts enhance firm efficiency in emerging markets? North-Western Journal of International Law \& Business, 40(3), 333-361. Retrieved from http://adu-lib-database.idm.oclc.org/login?url=https://www-proquest-com.adu-lib-database.idm.oclc.org/do cview/2429821034? accountid $=26149$

Flood, J., \& McCullough, A. (2020). Block chain's future: Can the decentralized blockchain community succeed in creating standards? The Knowledge Engineering Review, 35. https://doi.org/10.1017/S0269888920000016

Goldenfein, J., \& Leiter, A. (2018). Legal engineering on the blockchain: 'Smart contracts' as legal conduct. Law and Critique, 29(2), 141-149. https://doi.org/10.1007/s10978-018-9224-0

Helfand, R. D. (2017). Big Data and Insurance: What Lawyers Need to Know and Understand. Journal of Internet Law, 21(3), 1, 3-35. Retrieved from http://adu-lib-database.idm.oclc.org/login?url=https://www-proquest-com.adu-lib-database.idm.oclc.org/do cview/1938844083? accountid $=26149$

Itp.net. (2019, 6 26). Salesforce introduces the First Low-Code Blockchain platform for CRM. Retrieved 1012 , 2020, from https://www.itp.net/; https://www.itp.net/619248-salesforce-introduces-the-first-low-code-blockchain-platform-for-crm

Jha, S. (2017, Oct 28). Inside hari marar's plan to make Bangalore airport the face of future airports [interviews]. The Economic Times. Retrieved http://adu-lib-database.idm.oclc.org/login?url=https://www-proquest-com.adu-lib-database.idm.oclc.org/do cview/1956184624? accountid $=26149$

Karafiloski, E., \& Mishev, A. (2017). Blockchain solutions for big data challenges: A literature review. Piscataway: The Institute of Electrical and Electronics Engineers, Inc. (IEEE). https://doi.org/10.1109/EUROCON.2017.8011213 
Kaur, A., \& kaur, R. (2018). Cloud Computing: A Focus on Security Issues in Cloud Computing Region. International Journal of Advanced Research in Computer Science, 9(2), 267-269. https://doi.org/10.26483/ijarcs.v9i2.5556

Kim, J. (2019). Why blockchain may be block chain's best cyber security option: With new and emerging security threats to blockchain projects, it's time to consider building decentralized security applications. Network World (Online), Retrieved from http://adu-lib-database.idm.oclc.org/login?url=https://www-proquest-com.adu-lib-database.idm.oclc.org/do cview/2183810119? accountid=26149

Kohli, C., Suri, R., \& Kapoor, A. (2015). Will social media kill branding? Business Horizons, 58(1), 35. https://doi.org/10.1016/j.bushor.2014.08.004

KPMG. (2018, Sep 06). Canada Newswire. Retrieved from http://adu-lib-database.idm.oclc.org/login?url=https://www-proquest-com.adu-lib-database.idm.oclc.org/do cview/2099822106? accountid $=26149$

Lawson-Body, A., Illia, A., \& Jimenez, J. (2006). Impact of Data Integration on CRM in the Electronic Commerce of SMES. Academy of Information and Management Sciences Journal, 9(1), 83-102. Retrieved from

http://adu-lib-database.idm.oclc.org/login?url=https://www-proquest-com.adu-lib-database.idm.oclc.org/do cview $/ 214630163$ ? accountid $=26149$

Lee, H. S. (2008). Selected antecedents of customer loyalty within a restaurant loyalty program: Perceived control, privacy concern, perceived value of a loyalty program, and willingness to disclose information (Order No. 3441060). Available from ProQuest Central. (849718737). Retrieved from http://adu-lib-database.idm.oclc.org/login?url=https://www-proquest-com.adu-lib-database.idm.oclc.org/do cview/849718737? accountid $=26149$

Lin, G., Lee, H., Chan, Y., Tsai, B., \& Wang, K. (2020). Transforming long-term care for elders in Taiwan: Leveraging supply chain information, AI and blockchain technology, Asia university team aims to improve financing, business performance, service quality and customer satisfaction. OR-MS Today, 47(2).

Lo, A. S., Im, H. H., Chen, Y., \& Qu, H. (2017). Building brand relationship quality among hotel loyalty program members. International Journal of Contemporary Hospitality Management, 29(1), 458-488. https://doi.org/10.1108/IJCHM-06-2015-0283

Maroofi, F., \& Amiri, S. (2016). Examine how data collection directly and indirectly, impacts CRM data quality and customer performance. Journal of Asian Scientific Research, 6(1), 9-23. https://doi.org/10.18488/journal.2/2016.6.1/2.1.9.23

Martinez, V., Zhao, M., Blujdea, C., Han, X., Neely, A., \& Albores, P. (2019). Blockchain-driven customer order management. International Journal of Operations \& Production Management, 39(6), 993-1022. https://doi.org/10.1108/IJOPM-01-2019-0100

Mearian, L. (2019). Researchers to launch intentionally 'vulnerable' blockchain at black hat. Framingham: Computerworld, Inc. Retrieved from http://adu-lib-database.idm.oclc.org/login?url=https://www-proquest-com.adu-lib-database.idm.oclc.org/do cview/2263684171? accountid $=26149$

Mohamad, A. G., \& Zabadi, A. M. (2020). Promoting a revamped CRM through internet of things and big data: An AHP-based evaluation. International Journal of Organizational Analysis, 28(1), 66-91. https://doi.org/10.1108/IJOA-12-2018-1602

Morkunas, M., Cernius, G., \& Giriuniene, G. (2019). Assessing business risks of natural gas trading companies: Evidence from GET Baltic. Energies, 12(14), 2647. https://doi.org/10.3390/en12142647

Moyo, I. L., Gumbo, V., Chikodza, E., \& Jones, B. (2019). An empirical study on the factors influencing the performance of financial institutions in Zimbabwe. International Journal of Finance \& Banking Studies, 8(4), 1-20. https://doi.org/10.20525/ijfbs.v8i4.514

Newsbites. (2019, Nov 12). Blockchain is changing digital marketing in many different ways. News Bites, Private Companies. Retrieved from http://adu-lib-database.idm.oclc.org/login?url=https://www-proquest-com.adu-lib-database.idm.oclc.org/do cview/2343473324? accountid $=26149$ 
Omar, N. A., Wel, C. A. C., Musa, R., \& Nazri, M. A. (2010). Program benefits, satisfaction and loyalty in retail loyalty program: Exploring the roles of program trust and program commitment. IUP Journal of Marketing Management, $9(4), \quad 6-28 . \quad$ Retrieved from http://adu-lib-database.idm.oclc.org/login?url=https://www-proquest-com.adu-lib-database.idm.oclc.org/do cview/817464647? accountid=26149

Pachamanova, D., Mancha, R., \& Kokina, J. (2017). Blockchain: Emergent industry adoption and implications for accounting. Journal of Emerging Technologies in Accounting, 14(2), 91. https://doi.org/10.2308/jeta-51911

Peterson, M. (2018). Blockchain and the future of financial services. The Journal of Wealth Management, 21(1), 124-131. https://doi.org/10.3905/jwm.2018.21.1.124

Pierro, M. D. (2017). What is the blockchain? Computing in Science \& Engineering, 19(5), 92-95. https://doi.org/10.1109/MCSE.2017.3421554

Power, B., \& Weinman, J. (2018). Revenue growth is the primary benefit of the cloud. IEEE Cloud Computing, 5(4), 89-94. https://doi.org/10.1109/MCC.2018.043221018

Prince, W. K., Yung-Cheol, B., \& Park, N. (2020). A data verification system for CCTV surveillance cameras using blockchain technology in smart cities. Electronics, 9(3), 484. https://doi.org/10.3390/electronics9030484

Pulwasha, I., Kuijpers, M. V., Azadeh, K., Aqsa, I., \& DeGouvia De Sa, M. (2020). Artificial intelligence: A new paradigm in obstetrics and gynaecology research and clinical practice. Cureus, 12(2).

Purcărea, T., \& Purcărea, A. (2017). Services marketing in the era of disruption and digital transformation. Romanian Economic and Business Review, 12(4), 7-26. Retrieved from http://adu-lib-database.idm.oclc.org/login?url=https://www-proquest-com.adu-lib-database.idm.oclc.org/do cview/2070369324? accountid $=26149$

PWC. (2018, Sep 01). ICT Monitor Worldwide. Retrieved from http://adu-lib-database.idm.oclc.org/login?url=https://www-proquest-com.adu-lib-database.idm.oclc.org/do cview $/ 2097937593$ ? accountid $=26149$

Reckoon. (2020, Feb 06). Reckoon's blockchain \& AI enabled solution is shaping the future of the retail industry: UK-based reckoon announces details of their blockchain \& AI enabled, "global shopping platform as a service" via their proprietary global Wish Basket shopping protocol (GloWS). Reckoon will hold initial exchange offerings on multiple exchanges. PR Newswire Retrieved from http://adu-lib-database.idm.oclc.org/login?url=https://www-proquest-com.adu-lib-database.idm.oclc.org/do cview $/ 2351277416$ ?accountid $=26149$

Rosenoer, J. (2019). Blockchain evolution transformation AT THE EDGE OF INNOVATION. The RMA Journal, 101(9), 44-48. Retrieved from http://adu-lib-database.idm.oclc.org/login?url=https://www-proquest-com.adu-lib-database.idm.oclc.org/do cview/2299167827? accountid $=26149$

Rust, K. (2019). Block-chain reaction: Why development of blockchain is at the heart of the legal technology of tomorrow. Legal Information Management, 19(1), 58-60. https://doi.org/10.1017/S1472669619000124

Scala, E., Price, C., \& Jennifer, D. (2016). An integrative review of engaging clinical nurses in nursing research. Journal of Nursing Scholarship, 48(4), 423-430. https://doi.org/10.1111/jnu.12223

Sharma, S. G., Ahuja, L., \& Goyal, D. P. (2018). Building secure infrastructure for cloud computing using blockchain. Piscataway: The Institute of Electrical and Electronics Engineers, Inc. (IEEE). https://doi.org/10.1109/ICCONS.2018.8663145

Sharma, T., Satija, S., \& Bhushan, B. (2019). Unifying blockhead and IoT: Security requirements, challenges, applications and future trends. Piscataway: The Institute of Electrical and Electronics Engineers, Inc. (IEEE). https://doi.org/10.1109/ICCCIS48478.2019.8974552

Shoaib, M., Lim, M. K., \& Wang, C. (2020). An integrated framework to prioritize blockchain-based supply chain success factors. Industrial Management \& Data Systems, 120(11), 2103-2131. https://doi.org/10.1108/IMDS-04-2020-0194

Shrestha, R., Nam, S. Y., Bajracharya, R., \& Kim, S. (2020). Evolution of V2X communication and integration of blockchain for security enhancements. Electronics, 9(9), 1338. 
https://doi.org/10.3390/electronics9091338

Shukla, D. (2019, Aug 01). Tech focus: How blockchain will upend customer experience. Electronics for You, Retrieved from http://adu-lib-database.idm.oclc.org/login?url=https://www-proquest-com.adu-lib-database.idm.oclc.org/do cview/2269409010?accountid=26149

Son, M., \& Kim, H. (2019). Blockchain-based secure firmware management system in IoT environment. Piscataway: The Institute of Electrical and Electronics Engineers, Inc. (IEEE). https://doi.org/10.23919/ICACT.2019.8701959

Sung-Bum, K., \& Dae-Young, K. (2016). The impacts of corporate social responsibility, service quality, and transparency on relationship quality and customer loyalty in the hotel industry. Asian Journal of Sustainability and Social Responsibility, 1(1), 39-55. https://doi.org/10.1186/s41180-016-0004-1

Thorn, B. (2018). Chanticleer holdings to launch crypto currency-based loyalty program. Nation's Restaurant News, Retrieved

from http://adu-lib-database.idm.oclc.org/login?url=https://www-proquest-com.adu-lib-database.idm.oclc.org/do cview/1985168320?accountid $=26149$

Tian, H., He, J., \& Ding, Y. (2019). Medical data management on blockchain with privacy. Journal of Medical Systems, 43(2), 1-6. https://doi.org/10.1007/s10916-018-1144-x

Veloutsou, C., \& Moutinho, L. (2009). Brand relationships through brand reputation and brand tribalism. Journal of Business Research, 62(3), 314. https://doi.org/10.1016/j.jbusres.2008.05.010

Vernon, M. (2000, Jun 07). An information store that is vital for CRM projects: ROLE OF THE DATA WAREHOUSE by mark Vernon: Data availability alone does not automatically make for good CRM, although observers believe that e-business databases will side-step many traditional problems [surveys edition]. Financial Times Retrieved from http://adu-lib-database.idm.oclc.org/login?url=https://www-proquest-com.adu-lib-database.idm.oclc.org/do cview $/ 248822537$ ? accountid $=26149$

Vijay, N. (2018, Jul 20). Blockchain is another emerging technology that holds immense potential for healthcare industry: Partha dey. PharmaBiz, Retrieved from http://adu-lib-database.idm.oclc.org/login?url=https://www-proquest-com.adu-lib-database.idm.oclc.org/do cview/2071983401? accountid=26149

Wang, B. (2018). niTROn blockchain conference will explore solutions and blockchain future. Moffett Field: Newstex.

http://adu-lib-database.idm.oclc.org/login?url=https://www-proquest-com.adu-libdatabase.idm.oclc.org/blo gs,-podcasts,-websites/nitron-blockchain-conference-will-explore/docview/2253596983/se-2?accountid=26 149

Wang, L., Xin (Robert), L., \& Lee, F. (2019). Unveiling the interplay between blockchain and loyalty program participation: A qualitative approach based on bubichain: SSIS. International Journal of Information Management, 49, 397. https://doi.org/10.1016/j.ijinfomgt.2019.08.001

Woo, S., Song, J., \& Park, S. (2020). A distributed oracle using Intel SGX for blockchain-based IoT applications. Sensors, 20(9), 2725. https://doi.org/10.3390/s20092725

\section{Copyrights}

Copyright for this article is retained by the author, with first publication rights granted to the journal.

This is an open-access article distributed under the terms and conditions of the Creative Commons Attribution license (http://creativecommons.org/licenses/by/4.0/). 